\title{
Title Protection Policy for Doctoral Nursing Education in Ontario, Canada
} Michelle Acorn

Primary Health Care - Global Health NP Co-ordinator/Lecturer, University of Toronto, Ontario, Canada

Lead NP, Lakeridge Health, Whitby, Ontario, Canada

\section{Policy Title}

Inclusion of the Title "Doctor" for Members of the College of Nurses of Ontario with doctoral education.

\section{Policy Rationale}

The standard for transforming health care and professional education is elevating. Advance practice nursing (APN) continues to evolve to meet complex health care system needs. Doctoral prepared Registered Nurses (RN) and Nurse Practitioners (NP) are not currently authorized to use the title "Doctor" related to professionally restrictive statutes.

\section{Background to the Issue}

According to the College of Nurses of Ontario (Personal Communication, 2014) there are 63 Nurses registered with Doctorate education, 29 of these are NPs. An RN, or an NP also recognized as a Registered Nurse in the Extended Class (RN (EC)) in Ontario are required to use their protected titles in nursing practice. Nurse Practitioners may add their specialty certifications to their title such as NP- Primary Health Care, Adult, Pediatric or Anesthesia [1].

The Nursing Act [2] and The Regulated Health Professions Act [3] restrict those who may use the title "doctor" when offering health care. Furthermore, members of the College of Nurses of Ontario are professionals not authorized to use the title "Doctor." For doctoral prepared nurses to communicate their education credential, they may only write out the degree granted as it appears on their diploma [4]

According to the Canadian Nurses Association [5] the minimum education preparation for APNs is a graduate degree. The American Academy of Colleges of Nurses [6] position paper advocates that entry into advance practice nursing change from a Master's Degree to the Doctor of Nursing Practice (DNP) degree by 2015. The Doctor of Philosophy $(\mathrm{PhD})$ is recognized as the highest distinction in scholarship, academic achievements and research across all disciplines including nursing [6]. The DNP practice doctorate is considered the terminal degree for the nursing profession concentrating on direct care, research utilization, improved delivery of care, patient outcomes and clinical systems management [6].

Nurse Practitioner scope of practice in the United States lags behind Ontario's present autonamous successes. Only eleven states permit NPs to practice independently without physician supervision similar to Ontario [7].

A Coalition from seven organizations including the American Academy of Nurse Practitioners, American College of Nurse Practitioners, and the National Organization of Nurse Practitioner Faculties convened regarding Doctor of Nursing (DNP) education and titling recommendations [8]. Utilization of the title "Doctor" by RNs or NPs represents an academic credential and is not limited to a professional program. Programs confer academic degrees permitting graduates to be "Doctors" and no one discipline owns the title. In the health arena, the term "Doctor" is not limited to medicine, and is seen in professions such as Doctor of Pharmacy or Physical Therapy. Recognition of doctorally educated nurses facilitates parity within the health care system exists [9].

\section{Publication History:}

Received: December 25, 2014

Accepted: February 14, 2015

Published: February 16, 2015

\section{Keywords:}

Title protection policy, Nursing education

Patient, public or professional confusion regarding doctoral prepared advance practice nurses may exist. The fact remains that the title protection "Doctor" is common to many disciplines and not just the domain of any one group of professions [6].

The Ontario Medical Association was not supportive of enabling and empowering NP scope of practice, specifically role autonomy for Bill 179 \& Regulation 965. Turf and title protection for "Doctor" is assumed. "Physician" should be the title to differentiate medicine versus nursing doctorate education. A critical mass of doctorally educated nurses does not exist presently, but cross border education is the lived reality. Momentum and professional equality will sustain the nursing doctorate movement.

\section{Review of the Literature}

Government initiatives have reduced many practice barriers in an equitable effort to improve access and cost contain, resulting in significant care improvements through autonomous and accountable NP practice [10]. Legislative and regulatory changes in Ontario have enabled NPs to improve quality care in an effort to capitalize on our health human resources. On July 1, 2011, Bill 179 (Regulated Health Professions Act) and Regulation 965 (Public Hospital Act) were proclaimed [4]. Final proclamation of remaining components of Bill 179 related to ordering broad diagnostic tests including CT, MRI, $\mathrm{x}$-rays and ultrasounds is anticipated to be announced soon. Adding title protection that is inclusionary for doctorate prepared nursing would align optimally to showcase for May Nursing Week.

The College of Nurses of Ontario (CNO) mandate is public protection. Self-regulation is a privilege granted to those professions that have demonstrated they can put the interests of the public ahead of their own professional interests. It recognizes that Ontario's nurses have the knowledge and expertise to regulate themselves as practitioners upon entry across baccalaureate and graduate education preparation [11]. In 2003, Alberta proclaimed the use of the title "Doctor" by an RN or NP can be used in academic, social or in conjunction with the delivery of nursing practice [14]. Ontario lags over ten years behind other provinces for doctorally prepared nursing title protection, but proudly leads the NP Canadian workforce.

"Corresponding Author: Dr. Michelle Acorn, DNP, NP PHC/Adult, MN/ACNP, BScN/PHCNP, ENC(C), GNC(C), CAP, CGP, Primary Health Care - Global Health NP Co-ordinator/Lecturer, University of Toronto, Ontario, Canada; E-mail: michelleacorn@gmail.com

Citation: Acorn M (2015) Title Protection Policy for Doctoral Nursing Education in Ontario, Canada. Int J Nurs Clin Pract 2: 116. doi: http://dx.doi.org/10.15344/23944978/2015/116

Copyright: () 2015 Acorn. This is an open-access article distributed under the terms of the Creative Commons Attribution License, which permits unrestricted use, distribution, and reproduction in any medium, provided the original author and source are credited. 
Citation: Acorn M (2015) Title Protection Policy for Doctoral Nursing Education in Ontario, Canada. Int J Nurs Clin Pract 2: 116. doi: http://dx.doi. org/10.15344/2394-4978/2015/116

Page 2 of 2

The Ontario Government created Health Force Ontario (2006) to ensure that Ontarians have access to the right number and mix of qualified health-care providers, when and where they are needed, now and in the future [10]. This include doctoral prepared nurses. Title protection of "Doctor" for either the $\mathrm{PhD}$ (research doctorate) or DNP (practice doctorate) or Dr NP for (doctoral prepared NP) exists in America, but is not yet recognized in Ontario [6]. The titles "Nurse, Nurse practitioner and Doctor" are protected under the Health Professional Act in Ontario [4]. Clinical Nurse Specialist lobbying remains underway for protection inclusion similar to NPs as advance practice nurses.

NP education prepares graduates to provide safe, high quality, costeffective, coordinated and comprehensive care grounded in evidencebased practice [9]. The landmark Ontario Randomized Control Trial involving almost 1600 families established that NPs were found to be both effective and safe almost 40 years ago in this sentinel primary care research [12]. A mixed methods NP role study involved nine Ontario hospitals. Positive NP attributes were evidenced in patient focused care, safety, trust, approachability and greater accessibility. Engagement of teams, breadth of knowledge, and bridging care gaps were valued NP roles. Contributions to improving consistency in care, knowledge of the medical care plan, capacity to liaison, central coordinating roles, and integrating within the interprofessional teams fully support the NP role [13].

Parity with other disciplines such as medicine, dentistry, physical therapy, and psychology who have established the practice doctorate as the standard entry into practice is the desired equitable outcome. Enabling NPs to be champions of change for optimal patient and organizational success leverages their knowledge and leadership capacity. This is not about NP trailblazing; it is capitalizing on doctorally prepared RNs and NPs as advance practice nursing health human resource champions. It is about the power to deliver safe quality care and optimize accountabilities. Care should not be defined by geography, professions or title restrictions. Legally recognizing nurses that have obtained doctoral education by authorizing the title "Doctor" for health provider parity, value and respect is another key step in advancing health care transformation and removing barriers for professional credibility by title protection use of doctor for nurses is key for transforming professional change.

\section{Policy Solution}

It is strongly recommended that we first amend the Nursing Act \& Regulated Health Professions Act for inclusion of the nurses and other professionals that have completed doctorate education for inclusion of title protection "Doctor". They may also utilize their nursing specialty RN/NP. Secondly, amend the College of Nurses of Ontario Scope of Practice document to include member access to be recognized as a "Doctor" and RN or NP. Third, engage the Ministry of Health and Long Term Care Nursing Secretariat who is PhD prepared for political will and timely support. Active dual endorsement by the Registered Nurses Association with over 40, 000 members and their $\mathrm{CEO}$ who is $\mathrm{PhD}$ prepared, and the Nurse Practitioner Association of Ontario with over 1500 members is sought. Aligning with the Canadian Nurses Association, whose President is also DNP prepared for an educational campaign role modeling public trust, the need for professional doctoral parity for national nursing consistency and title portability is paramount.

\section{References}

1. College of Nurses of Ontario (2011) Nurse Practitioner Standard.
2. Nursing Act, 1991, ONTARIO REGULATION 275/94.

3. Regulated Health Professions Act, 1991, S.O. 1991, CHAPTER 18.

4. College of Nurses of Ontario (2014).

5. Canadian Nurses Association (2003) Joint Position Statement: Doctoral Preparation in Nursing.

6. American Association of Colleges of Nursing (2004) Position Statement on the Practice Doctorate in Nursing.

7. Chrisitian S, Dower C, O'Neil E (2007) Overview of Nurse Practitioner Scopes of Practice in the United States, University of California.

8. Understanding the Doctor of Nursing Practice (2007).

9. CNA Advanced Practice Nursing Framework (2008).

10. Health Force Ontario (2013).

11. College of Nurses (2013) Membership Totals.

12. van Soeren, M, Hurlock-Chorostecki C, Reeves Scott (2011) The role of the nurse practitioners in hospital settings: implications for interprofessional practice. Journal of Interprofessional Care 25: 245 -251.

13. American Association of Colleges of Nursing (2014) The Doctor of Nursing Practice (DNP).

14. Alberta Health Professions Act (2003).

15. Mundinger M, Kane R, Lenz E, Totten A, Tsai W, et al. (2000) Primary Care Outcomes in Patients Treated by Nurse Practitioners or Physicians. JAMA 28: 59-86.

16. Glasgow MES (2011) Role development for doctoral advanced practice nurse, New York: Springer Publishing Company.

17. Moran K, Burson R, Conrad D (2014) The doctor of nursing practice scholarly project, USA: Jones \& Bartlett Learning. 